\title{
Ground nesting birds in roadside borders of the Argentine Pampas: habitat use and predation risk of artificial nests
}

\author{
Daniela María Depalma ${ }^{1,2,3}$ \& Myriam Emilia Mermoz ${ }^{1}$
}

1 Instituto de Ecología, Genética y Evolución de Buenos Aires (IEGEBA-CONICET), Buenos Aires, Argentina.
2 Departamento de Ecología, Genética y Evolución, Universidad de Buenos Aires, Buenos Aires, Argentina.
3 Corresponding author: danieladepalma@ege.fcen.uba.ar

Received on 19 February 2019. Accepted on 18 November 2019.

\begin{abstract}
Habitat loss and fragmentation have led to grassland bird declines, with ground nesters particularly vulnerable. Roadsides could provide habitat, although their suitability depends on several roadside and field characteristics. Vegetation structure determines foraging and nesting site availability. In addition, road delimits sharp edges where the activity of nest predators is usually higher, whereas herbaceous vegetation determines ground nest concealment. Trees could provide lookouts to predators, and modified habitat and woodlands in surrounding fields could offer additional resources to predators. Our objective was to assess habitat suitability for ground nester birds in roadsides belonging to one modified grassland of the Argentine Pampas. We surveyed birds (90 plots) and monitored artificial nests (60 plots) in different road types: unpaved, paved of one-lane per side, and paved of two-lanes per side. Within each road type, we evaluated the relationship that ground nesters abundance had with vegetation structure of roadsides and surrounding fields. In addition, we related predation of artificial nests with the proximity to the road, roadside vegetation, and modified land and woodlands of surrounding fields. We made 2832 records of 84 species using roadsides, including 1083 records of 13 ground nesting species. Abundance of ground nesters increased with tall grass cover of roadsides and decreased with the number of native trees within roadsides. Roughly half (31/60) of the artificial nests were predated and $82.6 \%$ of the identified egg-marks were of mammal teeth. Nest predation decreased with nest proximity to the road. Our results emphasize the importance of tall grass cover of roadsides for the conservation of ground nesting species, and the necessity of monitoring natural nests in order to clarify the effect of trees, proximity to the road, and other environmental variables on nest success.
\end{abstract}

KEY-WORDS: corridors, field margins, grassland birds, habitat remnants, survival analysis.

\section{INTRODUCTION}

Habitat loss and fragmentation have led to the decline of grassland bird populations worldwide (Askins et al. 2007, Zuckerberg et al. 2009, Azpiroz et al. 2012, Reif 2013). Amongst them, ground nesting birds are particularly vulnerable due to the greater exposure of eggs, chicks and incubating adults to mammalian and bird predators (Pietz et al. 2009, Fletcher et al. 2010), which increases with habitat fragmentation due to higher amounts of habitat edges with which predators are associated (Evans 2004, Huijser \& Clevenger 2006). Thus, conservation researchers have become interested in habitat remnants that could benefit the conservation of these species (Weidman \& Litvaitis 2011, Duchardt et al. 2016, Port $\&$ Schottler 2017). In this context, it has been proposed that roadside networks can provide habitat (Meunier et al. 1999, Bergin et al. 2000), although their suitability for grassland birds depends on several factors affecting bird abundance and nest predation.

One key factor influencing the abundance of grassland birds in roadsides is vegetation structure, which determines the availability of shelter, foraging sites and nesting sites (Meunier et al. 1999, Kociolek et al. 2011). Moreover, habitat availability in the surrounding fields may also promote bird abundance in roadsides (Huijser \& Clevenger 2006), while woodlands and modified land (i.e., crops or human settlements) have exhibited a negative association with the abundance of birds inhabiting grassland remnants (Leston 2013, Dotta et al. 2016, Pretelli et al. 2018). Some grassland birds might avoid these areas since woodlands can increase the abundance of specialist predators (Vickery et al. 2009, Ellison et al. 2013) and brood parasites (Patten et al. 2006, Pietz et al. 2009), and modified land may offer resources to generalist predators (Evans 2004, BenítezLópez et al. 2010).

In addition, roadside characteristics can affect ground nesting bird populations due to their influence on nest predation risk. Nest detectability by predators decreases with greater structural complexity of the vegetation, which contributes to nest concealment (Weidinger 2002, Conover et al. 2011). In contrast, detectability may be increased by the proximity to trees, which offer lookouts 
to avian predators that use visual cues (Söderström $e t$ al. 1998, Bergin et al. 2000, Flaspohler et al. 2001) as well as to brood parasites (Patten et al. 2006). Moreover, roads lack structural complexity, and nest proximity to the road could imply the proximity to hard habitat edges where predator activity is higher (Fletcher \& Koford 2003, Weldon \& Haddad 2005, King et al. 2009). Likewise, predation can depend on wider scale factors such as the prevalence of woodlands and modified lands, which offer resources to generalist predators and may enhance their abundance in the landscape (Hogrefe et al. 1998, Vickery et al. 2009, Ellison et al. 2013).

Analyzing factors that affect both abundance and predation risk, therefore, constitutes an appropriate method to assess roadsides' suitability for birds in threatened grasslands. In particular, some of the most important Neotropical grasslands are those of southeastern South America, constituted by a part of Uruguay, southern Brazil and mainly by the Pampas in Argentina (Soriano et al. 2001). The conservation status of the Pampas is critical since currently more than $75 \%$ of their extent has been converted into croplands (Viglizzo et al. 2011). Such habitat loss has caused a decrease in the abundance and distribution of many grassland bird species, including a high proportion of ground nesting birds (Fraga 2003, Di Giacomo \& Di Giacomo 2004, Filloy \& Bellocq 2007, Azpiroz et al. 2012). Roadside conservation and management practices are still uncommon in the region, although it has been reported that ground nesting birds and many other bird species use roadsides more frequently than adjacent pastures and crops (i.e., soy and maize, Leveau \& Leveau 2011), and that grassland nesting bird richness increase with the amount of roadside borders in rural areas (Codesido \& Bilenca 2011).

Our objective here was to assess breeding habitat suitability for ground nesting birds in roadsides belonging to one modified grassland of the Argentine Pampas. In particular, we analyzed the effects that roadside and surrounding field characteristics have on bird abundance and nest predation. To achieve that aim, in different road types, we performed bird surveys and evaluated the relationship of bird abundance with vegetation structure of roadsides and surrounding fields. Additionally, we conducted an experiment with artificial nests to identify nest predators, and to evaluate the effects that proximity to the road and vegetation structure of roadsides and surrounding fields have on ground nest predation.

\section{METHODS}

\section{Study area and sampling sites}

Field work was carried out near General Madariaga city $\left(37^{\circ} 0^{\prime} 7^{\prime \prime} \mathrm{S} ; 57^{\circ} 8^{\prime} 10^{\prime \prime} \mathrm{W}\right)$, Buenos Aires province, Argentina, within the flooding Pampa. In the flooding Pampa, mean temperature varies from $23^{\circ} \mathrm{C}$ in January to $13^{\circ} \mathrm{C}$ in July with mean annual precipitation of 1000 $\mathrm{mm}$ (Soriano et al. 2001). The area exhibits subtle topographic variations (most lands are less than $4 \mathrm{~m}$ above sea level), with lowlands remaining flooded for long periods. For this reason, the flooding Pampa is the least cropped portion of the Pampas and the distribution of many native bird species is restricted to this area, giving it a high conservation value (Codesido et al. 2011). However, since 1990's increasing crop lands and cattle production pose conservation implications (Agra et al. 2015). Vegetation in this area is a mosaic of extensive grasslands disrupted by wetlands with a high presence of Schoenoplectus californicus (Family Cyperaceae), Solanum glaucophyllum (Solanaceae), Senecio spp. (Asteraceae), and Typha spp. (Typhaceae), and by smaller patches of native woodlands comprised mostly of Celtis ehrenbergiana (Cannabaceae) in the higher areas (Vervoorst 1967). About $70 \%$ of the area is used for cattle production, with land crops covering 20\% (Codesido \& Bilenca 2011) and the remaining land consisting in deep water bodies, tree plantations, dunes, salt marshes, and urban areas (Baldi $\&$ Paruelo 2008). We conducted our study in OctoberNovember 2015, which comprises the peak of the breeding season for most bird species (de la Peña 2015). Within an area of approximately 80,000 ha, we sampled roads representing the three types of roads present in the area. Sampled road types were: unpaved roads of local use (three roads), one paved road of one-lane per side that connects General Madariaga city with Las Armas town, and one paved road of two-lanes per side that connects General Madariaga city with Pinamar city. All these roads could be considered as transects, being the mean distance among transects' midpoints $20.4 \mathrm{~km}$ (range: 6.2-26.5 $\mathrm{km}$ ). Road types have different speed limits (two-lanes per side: $110 \mathrm{~km} / \mathrm{h}$, one-lane per side: $100 \mathrm{~km} / \mathrm{h}$, unpaved: $60 \mathrm{~km} / \mathrm{h}$ ). In addition, road types could have different traffic intensity in terms of vehicles per unit of time. The two-lanes per side probably has the highest amount of vehicles per unit of time since it connects two cities and leads to one of the most important touristic spots along the coast of Buenos Aires province. We further considered the potential differences among road types from a birds' perspective (see Statistical analysis), since it has been reported that traffic-related factors such as noise can affect bird distribution and behavior (Seiler 2001, Kociolek et al. 2011).

Along each road we selected points at random distances from the beginning of the sampling section of the road (one-lane per side: $n=30$ points, two-lanes per side: $n=30$, unpaved: $n=30$ ), being the minimum distance between neighbour points $400 \mathrm{~m}$. Then, in each point we established one sampling plot, which was a 
fragment of roadside borders of 200-m length that was centred in the point and comprised the area between the edge of the road, either right or left, and the fence of its adjacent field. Since the width of our roadside borders had a range of $6.0-45.6 \mathrm{~m}$, the area of our sampling plots varied between 0.12 and 1.08 ha.

\section{Bird sampling}

In each sampling plot, we performed bird surveys using 10 -min point counts, during the first $4 \mathrm{~h}$ after sunrise and in good weather conditions (Bibby 2000). Sampling plots were divided in two 100-m length subplots, and each of two observers recorded every bird seen or heard in one subplot, disregarding those birds flying above the plot. We considered that there was minimal need to account for detection probability given the high visibility in these roadside borders mainly constituted by grassland, and because each observer recorded individuals at a maximum distance of $50 \mathrm{~m}$ (Smucker et al. 2005). To increase the accuracy of abundance estimations, we surveyed each plot twice (one visit during October and the other one during November), and the maximum number of individuals recorded for each species was considered the species' abundance. Later, we classified species by their nesting sites (de la Peña 2015). We only considered in further analyses the abundance of those grassland birds that build their nests directly on the ground, or very close to the ground on clumps of grasses (de la Peña 2015), hereafter designated as "ground nesting birds". We also noted which of these ground nesting bird species are considered as grassland obligates (Azpiroz \& Blake 2009). Scientific nomenclature was in accordance with South American Classification Committee (SACC-American Ornithologists' Union, Remsen-Jr. et al. 2019).

\section{Vegetation sampling}

In each sampling plot, we estimated local vegetation cover based on three transects perpendicular to the road, separated by $75 \mathrm{~m}$. One observer (D. Depalma) measured the length of intersection of each vegetation type (see below) on each transect, by walking along the transect using a measuring tape (Matteucci \& Colma 1982). When there was no accessibility (e.g., wetlands), the length of intersection of vegetation types was measured with a rangefinder (Redfield ${ }^{\circledR}$ Raider $^{\mathrm{TM}}$ 550). Then we expressed the lengths of intersection as percentages. Finally, in every plot, for each vegetation type we used the average of the three transects. The perpendicular orientation of transects allowed us to account for the vegetation gradient present in roadside borders.

Vegetation types consisted of short grass (areas consisting mainly in grasses shorter than $30 \mathrm{~cm}$ ), tall grass (grassland of 30-80 $\mathrm{cm}$ height dominated by the exotic pasture Festuca arundinacea -with low presence of Bromus catharticus, Dactylis glomerata, Triticum aestivum, Nassella neesiana, Avena sativa and Phalaris minor), Pampa grass (individuals of the native grass Cortaderia selloana of $0.7-2 \mathrm{~m}$ height), dicotyledoneous (grassland of $30-80 \mathrm{~cm}$ height dominated by exotic flowering plants with non-negligible presence of native flowering plants), wetland vegetation (S. californicus and Typha spp.), water, native trees (C. ehrenbergiana and Scutia buxifolia) and exotic trees (mainly Populus spp.). All flowering plants were classified into the finest level possible, and thus we determined that exotic flowering plants belonging to the family Brassicaceae represented $55 \%$ of the total flowering plants, and plants belonging to the native species Matricaria chamomila represented 32\%. We also counted individual trees within the entire area of each sampling plot. In all statistical analyses, the number of trees was incorporated instead of tree cover, since it may be a more accurate variable to measure in linear fragments (McDonald \& Johnson 1995; Table 1). The number of trees has been also mentioned as one of the major factors influencing bird richness and abundance in field borders (Hinsley \& Bellamy 2000).

In addition, while measuring vegetation cover at plot scale, we described the cover of surrounding fields. Later, we estimated the cover of surrounding fields in satellite images of November 2015 (Image ${ }^{\odot} 2017$ Digital Globe, source: Google ${ }^{\circledR}$ Earth $^{\mathrm{TM}}$ ) with Google Earth Pro Software (Sullivan 2009). Validating the images with our observations recorded in the field, we measured the percentage of short grassland, seminatural grassland, native woodland, exotic woodland, and modified land within a $200-\mathrm{m}$ radius circular area around each plot (Table 1). Short grassland consisted in extremely short grass intensively grazed or mowed. Seminatural grassland consisted in tall grass often moderately disturbed by grazing. Modified land consisted in crops (mainly maize and soy), stubble, and human settlements. Finally, native woodland consisted in groups of trees mainly composed by C. ehrenbergiana and S. buxifolia, and exotic woodland were composed by at least $80 \%$ of exotic trees (mostly Eucalyptus spp., Table 1). We considered the percentage of seminatural grasslands as available habitat for grassland birds, and the percentage of native and exotic woodlands and modified land as potential sources of predators.

\section{Artificial nests experiment}

Artificial nests carry a certain bias since their visual signals (absence of parental activity) and chemical signals differ from those of natural nests, and thus they may underestimate or overestimate the actual predation risk, according to nest type and predator community composition (Thompson \& Burhans 2004). However, they provided us a possibility to evaluate the relationship 
Table 1. Characteristics of roadside borders of the Argentine Pampas. Frequencies of occurrence and mean value \pm standard deviation per sampling plot are shown. Ranges are in parentheses.

\begin{tabular}{lcc}
\hline Vegetation type & Frequency of occurrence (\%) & Value per plot \\
\hline Roadsides & & \\
Short grass (\%) & 86.6 & $10.8 \pm 10.5(0-39.5)$ \\
Tall grass (\%) & 70 & $32.7 \pm 28.5(0-95.8)$ \\
Pampa grass (\%) & 47.7 & $5.7 \pm 10.1(0-48.5)$ \\
Dicotyledonous (\%) & 82.2 & $5.4 \pm 6.9(0-32.9)$ \\
Wetland (\%) & 72.2 & $21.4 \pm 21.8(0-87)$ \\
Native trees (n) & 55.5 & $7.4 \pm 14.5(0-71)$ \\
Exotic trees (n) & 5.5 & $1.4 \pm 7.6(0-50)$ \\
Total trees (n) & 58.8 & $8.8 \pm 17.4(0-89)$ \\
Surrounding fields & & \\
Seminatural grassland (\%) & 46.6 & $12.3 \pm 17.2(0-72.1)$ \\
Short grass (\%) & 60 & $2.7 \pm 23.9(0-81.2)$ \\
Wetland (\%) & 76.6 & $14.4 \pm 15.1(0-52.8)$ \\
Modified land (\%) & 44.4 & $8.6 \pm 14.3(0-55.4)$ \\
Native woodland (\%) & 43.3 & $1.3 \pm 2.6(0-11.5)$ \\
Exotic woodland (\%) & 22.2 & $0.6 \pm 1.4(0-6.5)$ \\
Total woodland (\%) & 66.6 & $2.5 \pm 3.8(0-24.19)$ \\
\hline
\end{tabular}

between predation risk and environmental variables through a field experiment, controlling for nest location, clutch size and differences in parental activity around the nest (Thompson \& Burhans 2004). In addition, we were able to identify types of predators by the marks left on artificial eggs (Zanette \& Jenkins 2000). Within a representative subsample of 60 plots (i.e., one-lane per side: $n=20$, two-lanes per side: $n=20$, unpaved: $n=20$ ), we placed one artificial nest made of hemp on the ground. To resemble the nesting sites of ground nesting birds, all nests were located beneath a clump of tall grass, therefore equally sheltered. Monitoring was performed every four days until predation occurred or during 16 days, which encompassed the approximate duration of laying plus incubation periods of most ground nesting passerines (de la Peña 2015). The artificial nest $(10.5 \mathrm{~cm}$ diameter $\times 5.5 \mathrm{~cm}$ depth) was always placed in the center of the $200 \mathrm{~m}$ of the plot, beneath the first clump of tall grass encountered by walking from the road into the roadside border. We used this method instead of selecting fixed locations because, due to the presence of wetlands within most roadsides, many locations were unsuitable for nest placement (Table 1). In each nest, we put two quail eggs (Coturnix coturnix): one natural egg and the other filled with paraffin and tied to the nest by a nylon thread (Svagelj et al. 2003). We considered the removal and/ or break of at least one of the eggs as a predation event. When predation was detected, nests were immediately removed and no longer monitored. After monitoring, we observed the natural and the paraffin-filled eggs and looked for marks. We interpreted the marks based on the criteria used by Cozzani \& Zalba (2012) to identify ground nest predators in Buenos Aires province. Thus, we considered incisor marks on the paraffin-filled egg as predation by small mammals, while bigger and deeper teeth marks, and horseshoe shape marks on the natural egg were considered as predation by medium-sized mammals. Likewise, unique, deep marks on the paraffinfilled egg were considered as predation by birds, and the presence of two marks separated by a distance of $0.9 \mathrm{~cm}$ was considered predation by ophidians.

\section{Statistical analysis}

All statistical analyses were conducted using the $\mathrm{R}$ environment ( $\mathrm{R}$ Core Team 2019). We evaluated the relationship between total abundance of ground nesting birds and environmental variables using a Generalized Linear Mixed Model (GLMM) with the "glmadmb" function of the "glmmADMB" package (Bolker et al. 2012). Since overdispersion occurred when adjusting the model to a Poisson distribution, we solved this problem by using a Negative Binomial distribution. We accounted for potential interdependencies among plots belonging to the same road type by incorporating "road type" as a random factor. Furthermore, since plots along unpaved roads were grouped in three different roads, we incorporated the random factor "road identity" 
nested within road type. The dependent variable in the model was total abundance of ground nesting birds. We considered nine candidate independent variables measured at plot scale: the percentage (\%) of short grass, tall grass, dicotyledonous, Pampa grass, wetland vegetation and water, the number of native trees, the number of exotic trees, and the number of total trees. We also considered five candidate independent variables of surrounding fields (200-m radius): available habitat for grassland birds (percentage of seminatural grassland), and sources of predators (percentage of native woodland, percentage of exotic woodland, percentage of total woodland and percentage modified land). Since sampling plots had different widths, we incorporated plot area as an offset, which specifies an a priori known component to be included in the linear predictor during fitting (Crawley 2012).

We evaluated the support for predictor variables by information theoretic procedures (Burham \& Anderson 2002), using the "MuMIn" package (Barton 2013). We used Akaike's information criterion corrected for small sample size (AIC). In order to improve the parsimony (in terms of model parameters) of the global model, and to avoid generating an excessively large set of models based on sample size which could lead to spurious results (Grueber et al. 2011), we only incorporated relevant parameters. In order to define relevant parameters, we first built 14 univariate models, each of them having one candidate independent variable as the only predictor. We incorporated to the global model only those variables that lowered the AICc in more than 2 units relative to the null model. Those variables were the percentage of tall grass within roadsides and the number of native trees within roadsides (the correlation between these two variables was not significant). In addition, we also included the interaction between both variables. We considered models with all possible combinations of the three final predictor variables and ranked them by their AIC. Finally, we obtained parameter estimates by averaging models with a $\triangle \mathrm{AIC}_{\mathrm{c}}<4$ from the best model, and calculated 95\% confidence interval limits of parameter estimates (Grueber et al. 2011).

To test the effects of environmental variables on artificial nests' survival we used a mixed Cox proportional hazards model (Cox 1972) with the "coxme" package (Therneau \& Therneau 2018). This model is an extension of survival analysis similar to a logistic regression, and is able to evaluate the relationship between independent variables and the rate of occurrence of predation (Santabárbara et al. 2016). As with the model of bird abundance, we accounted for potential interdependencies among plots belonging to the same road and road type by incorporating the random factor "road identity" nested within the random factor "road type". The dependent variable was composed of the survival time (days) and the occurrence of predation ( 0 or 1$)$. The coefficient of an independent variable indicates its relationship with the occurrence of predation: a positive coefficient means that the variable is positive associated with the occurrence of predation. Coefficients were calculated by the partial maximum likelihood method. Likewise, for every independent variable the model estimates a Hazard Ratio (HR). A HR > 1 indicates that the variable is positively associated with the probability of predation, while a HR $<1$ indicates the opposite. We considered nine candidate independent variables measured at plot scale: the percentage (\%) of short grass, tall grass, dicotyledonous, Pampa grass, wetland vegetation and water, the number of native trees, the number of exotic trees, and the number of total trees. We also considered four candidate independent variables of surrounding fields (sources of predators within the 200-m radius): percentage of native woodland, percentage of exotic woodland, percentage of total woodland, and percentage of modified land.

To improve the parsimony of a potential global model, we first built one univariate mixed model to test the effect of each independent variable on survival separately, in order to further incorporate relevant parameters only. The only independent variable that had a significant effect on survival was "distance to road". We checked the assumptions about the linear functional form of the independent variables and hazards proportionality (i.e., the ratio of the survival rates remaining constant through time; Santabárbara et al. 2016). To accomplish this, we deleted two nests belonging to the two-lanes per side road that impeded the linear functional form of the variable "distance to road". These nests (i.e., outliers) were removed from all the analyses.

\section{RESULTS}

\section{Bird abundance}

We made 2832 records of 84 species using roadside borders. Amongst them, 1083 individuals (38.2\%) belonging to 13 species (15.5\%) were ground nesting species (Appendix I). Seven of these species are considered grassland obligates (Leistes superciliaris, Anthus correndera, Sicalis luteola, Embernagra platensis, Vanellus chilensis, Nothura maculosa and Rynchotus rufescens; Appendix I). As shown by the GLMM, ground nesting birds' abundance was positively associated with the percentage of tall grass within roadsides, and negatively associated with the number of native trees within roadsides (Table 2).

\section{Survival of artificial ground nests}

Of the 60 artificial nests we set out, 31 were predated within the 16-day period (one-lane per side: $n=10$, two- 
lanes per side: $n=10$, unpaved: $n=11)$. Thus, artificial nest survival was $48.3 \%$. According to the criteria used by Cozzani $\&$ Zalba (2012), $43.7 \%$ of predated nests (14 nests) exhibited small mammal marks, $15.6 \%$ (5 nests) were predated by medium sized-mammals, $9.4 \%$ (3 nests) were predated by birds and $3.1 \%$ (1 nest), by ophidians (Fig. 1). In $25 \%$ of nests (8 nests), we could not identify the predator, since in five cases the artificial egg had non identifiable marks (Fig. 1), and in three cases it had been removed. In such situations, we could not identify the predator using the natural egg either, since it had been removed in four nests, and it exhibited unidentifiable marks in the remaining nests.
Moreover, during field work we detected potential mammalian predators: Galictis cuja (Order Carnivora), Conepatus chinga (Order Carnivora), Cavia aperea (Order Rodentia) and Didelphis albiventer (Order Didelphimorphia). We also detected potential ophidian predators: Liophis poecilogyrus and Liophis anomalus (Order Squamata). Likewise, we recorded potential avian predators during bird surveys: Caracara plancus, Milvago chimango, Chroicocephalus maculipennis, Circus buffoni and Guira guira (Appendix I).

As shown by the results of mixed univariate Cox regressions, only distance to road had a significant effect on nest survival. The probability of nest predation was

Table 2. Candidate Generalized Linear Mixed Models with factors influencing the abundance of grassland ground nesting bird species in roadside borders of the Argentine Pampas, listed in decreasing order of importance. Only those models with a $\triangle \mathrm{AIC}_{\mathrm{c}}<4$ from the best model and the null model are included. Averaged estimates of parameters are shown in the second part of the table. Those parameters whose 95\% Confidence Intervals excluded 0 are in bold. K: number of parameters. TGR: tall grass of roadsides; NTR: native trees of roadsides; TGR*NTR: interaction term. SE: unconditional Standard Error. CI: 95\% Confidence Interval.

\begin{tabular}{|c|c|c|c|c|c|c|c|}
\hline \multicolumn{3}{|l|}{ Candidate models } & $\mathbf{K}$ & Log-likelihood & $\mathrm{AIC}_{\mathrm{c}}$ & $\Delta \mathrm{AIC}_{\mathrm{c}}$ & Weight \\
\hline \multicolumn{3}{|l|}{ TGR + NTR } & 6 & -262.22 & 537.5 & 0 & 0.58 \\
\hline \multicolumn{3}{|l|}{ TGR } & 5 & -264.39 & 539.5 & 2.04 & 0.21 \\
\hline \multicolumn{3}{|c|}{ TGR + NTR + TGR*NTR (Global model) } & 7 & -262.1 & 539.6 & 2.13 & 0.2 \\
\hline \multicolumn{3}{|c|}{ Null model } & 4 & -268.91 & 546.3 & 8.83 & 0.01 \\
\hline Model averaging & Estimate & SE & & CI & \multicolumn{3}{|c|}{ Relative importance } \\
\hline TGR & 0.247 & 0.07 & & $0.097,0.397$ & \multicolumn{3}{|c|}{1} \\
\hline NTR & -0.092 & 0.07 & & $-0.229,-0.005$ & \multicolumn{3}{|c|}{0.79} \\
\hline TGR*NTR & 0.001 & 0.02 & & $-0.073,0.119$ & \multicolumn{3}{|c|}{0.2} \\
\hline
\end{tabular}
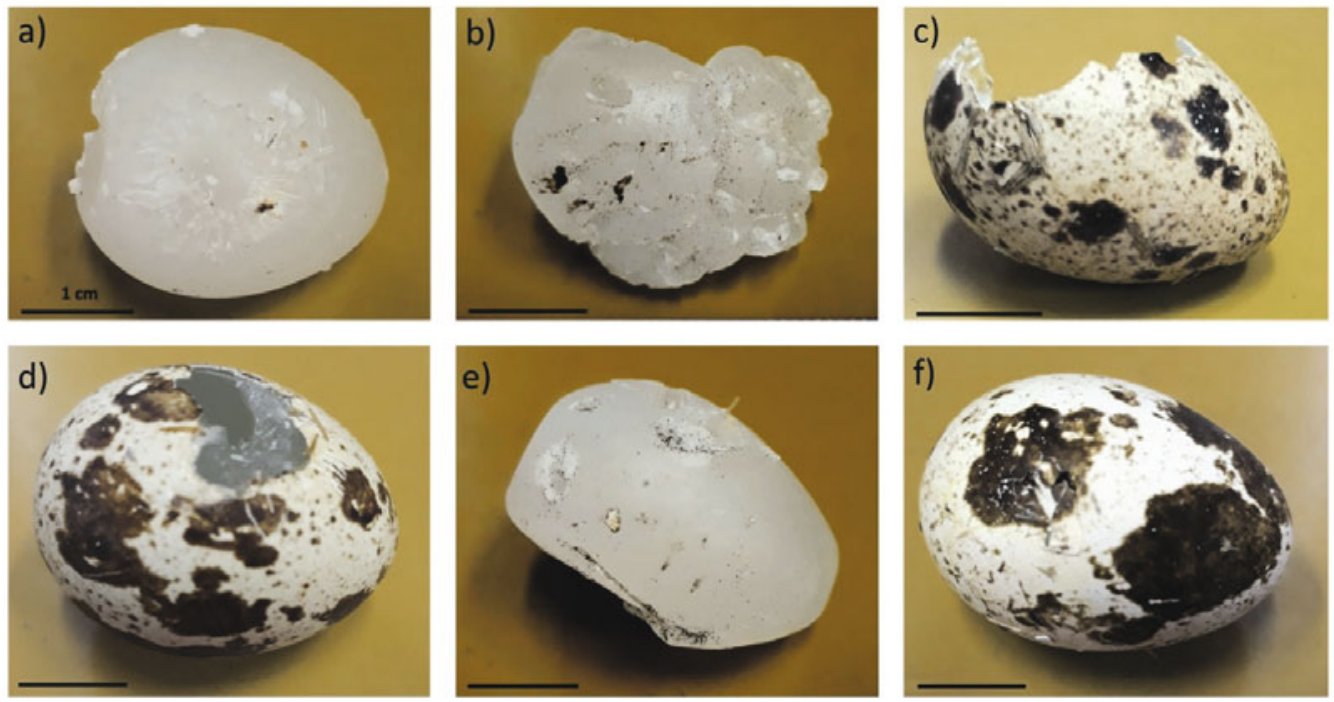

Figure 1. Predated natural and paraffin-filled Coturnix coturnix eggs on roadside borders of the Argentine Pampas. Examples of marks produced by small-sized mammals' incisors (A), medium-sized mammals' teeth marks $(\mathbf{B})$, a horseshoe-shaped mark produced by a medium-sized mammal $(\mathbf{C})$, one unique bird's beak mark $(\mathbf{D})$, two marks produced by an ophidian predator $(\mathbf{E})$ and one unidentifiable mark $(\mathbf{F})$. 
positively associated with the distance to $\operatorname{road}(P<0.05$; Table 3, Fig. 2). Nevertheless, the probability of nest predation also exhibited a marginal positive association with the number of native trees within roadsides $(P=$ 0.05 , Table 3).

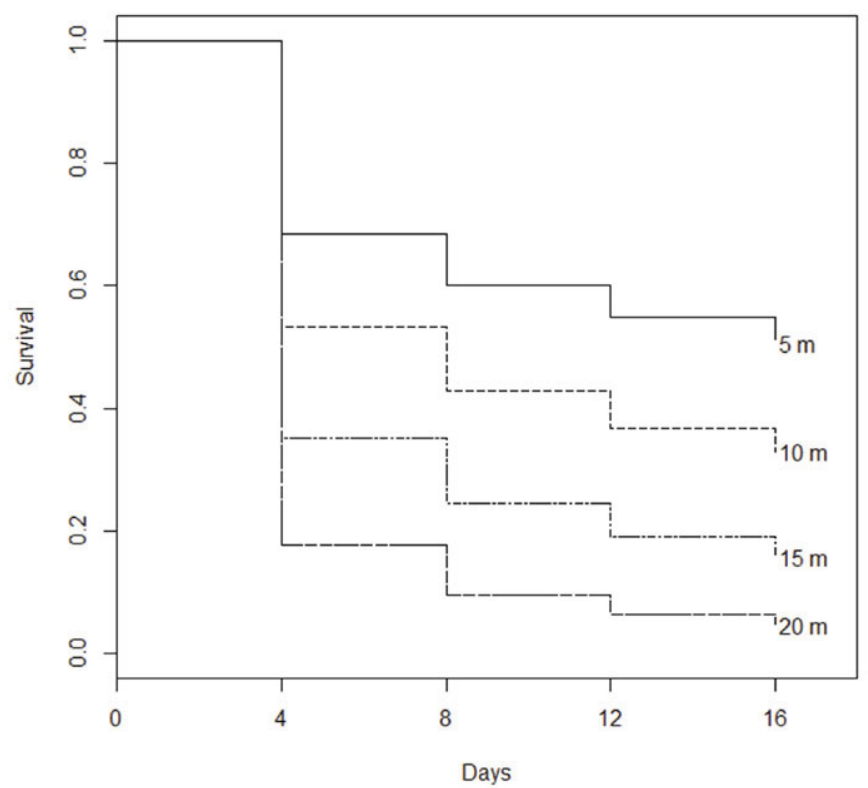

Figure 2. Expected survival curves for artificial nests located at different distances to the road in roadside borders of Argentine Pampas. Survival curves were built by fitting a mixed Cox proportional hazards model with distance to the road as the predictor variable. Predicted survival for nests located at 5, 10, 15 and $20 \mathrm{~m}$ from the road are shown.

\section{DISCUSSION}

In order to assess the suitability of roadsides for ground nesting birds in one modified grassland of the Argentine Pampas, we evaluated the influence of roadside factors and surrounding field factors on bird abundance, and on the predation of artificial nests. We found that bird abundance was positively associated with tall grass cover of roadsides and negatively associated with the number of native trees of roadsides, while evidence of predation decreased with proximity of nests to the road.

Regarding bird abundance, our results indicate that tall grass cover of roadsides favors their use by ground nesting birds, while the number of native trees reduces it. Similarly, it has been previously reported that ground nesting birds of the Pampas such as Sicalis luteola use grassy field margins more frequently than margins with trees (Leveau \& Leveau 2011). In another study of birds inhabiting field margins of the Argentine Espinal region, authors found that while total bird density increased with the number of trees, the density of some ground nesters decreased (Di Giacomo \& Lopez-de-Casenave 2010). In this sense, it is possible that tall grass increase the amount of escape cover and nest concealment for most ground nesters considered in our study (Isacch \& Martínez 2001, Davis 2005), while native trees in the proximities imply higher rates of nest predation and parasitism (Flaspohler et al. 2001, Patten et al. 2006, Pietz et al. 2009). It is not clear why only native trees, rather than total trees,

Table 3. Factors influencing predation of artificial nests in roadside borders of Argentine Pampas, tested by Mixed Cox Logistic Regression models. Regression coefficient and hazard ratio for the predictor variable of each of the univariate models are shown. Significant predictor variables $(P<0.05)$ are in bold.

\begin{tabular}{lccc}
\hline Univariate model & Coefficient & $\boldsymbol{P}$-value & Hazard ratio \\
\hline Short grass & 0.005 & 0.57 & 1.01 \\
Tall grass & -0.005 & 0.41 & 0.99 \\
Pampa grass & 0.014 & 0.5 & 1.01 \\
Dicotyledonous & -0.036 & 0.27 & 0.96 \\
Wetland vegetation & 0.007 & 0.43 & 1.01 \\
Water & -0.005 & 0.73 & 0.99 \\
Native trees & 0.02. & 0.05 & 1.02 \\
Exotic trees & -0.02 & 0.37 & 0.97 \\
Total trees & 0.006 & 0.41 & 1.01 \\
Distance to road & $\mathbf{0 . 1 0 2 *}$ & $\mathbf{0 . 0 2}$ & $\mathbf{1 . 1 1}$ \\
Modified land & $<-0.001$ & 0.21 & 0.99 \\
Native woodland & 0.028 & 0.71 & 1.02 \\
Exotic woodland & 0.105 & 0.37 & 1.11 \\
Total woodland & $<-0.001$ & 0.97 & 0.99 \\
\hline
\end{tabular}

$* P<0.05$

$\cdot P<0.1$ 
were negatively associated with bird abundance. One explanation is that native trees attract more predators than exotic trees. For example, in the Pampas, insectivorous birds usually prefer to forage on native trees than on exotic ones (Cueto \& Lopez-de-Casenave 2002). Therefore, native trees could attract some insectivorous birds that predate nests opportunistically, and thus represent an additional predation pressure. Another explanation is that native trees were more abundant than exotic ones in roadsides (Table 1) and formed continuous lines along field fences, which could provide more shelter to predators, and be perceived by sharp edges by birds (Fletcher \& Koford 2003, Weldon \& Haddad 2005).

Unlike local vegetation of roadsides, the cover of surrounding fields did not relate with bird abundance. On the one hand, the lack of associations between bird abundance and the cover of seminatural grasslands in the landscape could suggest that during the breeding season birds travel short distances to fulfill their requirements, and forage within nest proximities rather than using surrounding alternative habitats (Robinson et al. 2004, Vickery et al. 2009). On the other hand, the lack of associations between abundance and sources of predation such as woodlands and modified lands could be related to the characteristics of our study area. Also in the flooding Pampa, Pretelli et al. (2018) found no negative effect of agriculture on the abundance of grassland specialist birds inhabiting grassland remnants, probably because in this region agriculture is often mixed with short grasses and pastures. In contrast, they did report a negative effect of a continuous forest matrix around grassland remnants on bird abundance, although our study area did not exhibit a forest matrix but rather small scattered patches of woodland, which could be perceived differently by birds.

Regarding nest predation, most marks left on artificial nests belonged to mammals. A high frequency of predation by mammals in our nests is consistent with other studies, which compared nest predation at different heights and reported that mammals were the most frequent predators of ground nests (Söderström et al. 1998, Colombelli-Négrel \& Kleindorfer 2009). As proposed for other habitat strips within modified landscapes, these roadsides could serve as corridors for mammals, which could predate nests in an opportunistic manner as they travel (Meunier et al. 1999, Conover et al. 2011).

Additionally, predation mostly due to mammals could explain the striking negative relationship between proximity to the road and the probability of predation. These animals are usually affected by the presence of roads (Seiler 2001, Benítez-López et al. 2010). Moreover, recent researches about animals killed by collisions in Argentine roads found dead individuals of some of the mammalian predators we detected during this study such as Didelphis albiventer, Galictis cuja and Cavia aperea (Attademo et al. 2011, Bauni et al. 2017). Therefore, it is possible that mammals do not prefer to forage in road proximities, but rather move along the road, parallel to it (Forman \& Alexander 1998, Meunier et al. 1999).

Nevertheless, the success of real nests may be influenced by additional factors. Real nests might not be exposed to the same predation pressures as artificial nests (Thompson \& Burhans 2004), and artificial nests can underestimate predation by birds due to the lack of parental activity (Söderström et al. 1998, Flaspohler et al. 2001). Thus we cannot reject based on our results the possibility that nest predation may be causing the negative relationship between bird abundance and native trees, and that native trees may have a significant, rather than marginal, positive effect on nest predation. During bird surveys, we detected avian predators perching on trees in roadsides (Appendix I), and trees could offer them lookouts during the predation of real nests (Flaspohler $e t$ al. 2001).

Another explanation, although not excluding, would be that the negative association between grassland birds and native trees is actually the result of a higher risk of nest parasitism near trees (Patten et al. 2006, Pietz et al. 2009). Within the Pampas, nest parasitism by the generalist brood parasite Molothrus bonariensis is one of the major causes of egg losses for nesting birds, due to the punctures performed on the host's eggs during inspection visits (Massoni \& Reboreda 2002). However, this icterid might not be able to break the thick shell of quail eggs (Svagelj et al. 2003). Likewise, it might not visit artificial nests frequently, since parasites' behavior is usually based on parental activity around the nest (Wilson et al. 1998). The monitoring of real nests would be necessary in order to test the potential implications of native trees for nest predation and parasitism. In addition, real nest monitoring could also clarify the effect of road proximity on ground nest success. Although our artificial nests were less likely to be predated in road proximities, chicks of natural nests that hatch and fledge closer to roads may be more exposed to collisions (Kociolek et al. 2011).

In summary, this paper highlights that roadside borders of the flooding Pampas are inhabited by a wide range of grassland bird species, including several grassland obligates, and their conservation value could be increased with the application of appropriate managements. Such managements should consider the importance of tall grass for ground nesting birds, as well as the negative effects of native trees on their abundance. Future studies that involve the monitoring of real nests are necessary in order to elucidate the potential effects of native trees, distance to the road, and other environmental variables on ground nest success. 


\section{ACKNOWLEDGEMENTS}

We thank Emilio M. Charnelli, Daniela R. Acosta, Natalia Mufato, Cecilia Zilli and Víctor Blanco for the assistance in the field, and Pablo Picca for the assistance in the determination of plant species. We appreciate the improvements in English usage made by Nicole Arcilla through the Association of Field Ornithologists' program of editorial assistance. D.M.D. was supported by a Doctoral Fellowship from the Consejo Nacional de Investigaciones Científicas y Técnicas (CONICET). M.E.M. is a Research Fellow of CONICET. This work was supported by a Neotropical Grassland Conservancy (NGC) Ritt-Kellogg Grant to M.E.M., and N.G.C. Equipment Grant and Student Grant to D.M.D. Authors have no conflicts of interest to disclose.

\section{REFERENCES}

Agra M., Bilenca D. \& Codesido M. 2015. Responses of birds to planting of Lotus tenuis pasture in the flooding Pampas, Argentina. Ети 115: 270-276.

Askins R.A., Chávez-Ramírez F., Dale B.C., Haas C.A., Herkert J.R., Knopf F.L. \& Vickery P.D. 2007. Conservation of grassland birds in North America: understanding ecological processes in different regions: "Report of the AOU Committee on Conservation". Ornithological Monographs 64: 1-46.

Attademo A.M., Peltzer P.M., Lajmanovich R.C., Elberg G., Junges C., Sanchez L.C. \& Bassó A. 2011. Wildlife vertebrate mortality in roads from Santa Fe province, Argentina. Revista Mexicana de Biodiversidad 82: 915-925.

Azpiroz A.B. \& Blake J.G. 2009. Avian assemblages in altered and natural grasslands in the northern Campos of Uruguay. Condor 111: $21-35$.

Azpiroz A.B., Isacch J.P., Dias R.A., Di Giacomo A.S., Fontana C.S. \& Palarea C.M. 2012. Ecology and conservation of grassland birds in southeastern South America: a review. Journal of Field Ornithology 83: 217-246.

Baldi G. \& Paruelo J.M. 2008. Land-use and land cover dynamics in South American temperate grasslands. Ecology \& Society 13: 6-23.

Bartoń K. 2013. MuMIn: multi-model inference. R package version 1.9.13.

Bauni V., Anfuso J. \& Schivo F. 2017. Mortalidad de fauna silvestre por atropellamientos en el bosque atlántico del Alto Paraná, Argentina. Revista Ecosistemas 26: 54-66.

Benítez-López A., Alkemade R. \& Verweij P.A. 2010. The impacts of roads and other infrastructure on mammal and bird populations: a meta-analysis. Biological Conservation 143: 1307-1316.

Bergin T.M., Best L.B., Freemark K.E. \& Koehler K.J. 2000. Effects of landscape structure on nest predation in roadsides of a mid western agroecosystem: a multiscale analysis. Landscape Ecology 15: 131143.

Bibby C.J., Burgess N.D., Hill D.A. \& Mustoe S.H. 2000. Bird census techniques. London: Academic Press.

Bolker B., Skaug H., Magnusson A. \& Nielsen A. 2012. The glmmADMB package. R package version 0.6-5.Burham K.P. \& Anderson D.R. 2002. Model selection and multimodel inference: a practical information - theoretic approach. New York: SpringerVerlag.

Codesido M. \& Bilenca D.N. 2011. Los pastizales y el servicio de soporte de la biodiversidad: respuesta de la riqueza de aves terrestres a los usos de la tierra en la provincia de Buenos Aires, p. 511-526. In: P. Laterra, E.G. Jobbágy \& J.M. Paruelo (eds.). Valoración de servicios ecosistémicos: conceptos, herramientas y aplicaciones para el ordenamiento territorial. Buenos Aires: INTA.

Codesido M., González-Fischer C. \& Bilenca D. 2011. Distributional changes of landbird species in agroecosystems of central Argentina. Condor 113: 266-273.

Colombelli-Négrel D. \& Kleindorfer S. 2009. Nest height, nest concealment, and predator type predict nest predation in Superb Fairy-wrens (Malurus cyaneus). Ecological Research 24: 921-928.

Conover R.R., Dinsmore S.J. \& Burger L.W. 2011. Effects of conservation practices on bird nest density and survival in intensive agriculture. Agriculture, Ecosystems \& Environment 141: $126-132$.

Cox D.R. 1972. Regression models and life-tables. Journal of the Royal Statistical Society: Series B (Methodological) 34: 187-202.

Cozzani N. \& Zalba S.M. 2012. Depredadores de nidos en pastizales del Parque Provincial Ernesto Tornquist (provincia de Buenos Aires, Argentina): importancia relativa bajo distintas intensidades de pastoreo. Hornero 27: 137-148.

Crawley M.J. 2012. The R book. Chichester: John Wiley \& Sons.

Cueto V.R. \& Lopez-de-Casenave J. 2002. Foraging behavior and microhabitat use of birds inhabiting coastal woodlands in eastcentral Argentina. Wilson Bulletin 114: 342-348.

Davis S.K. 2005. Nest-site selection patterns and the influence of vegetation on nest survival of mixed-grass prairie passerines. Condor 107: 605-616.

de la Peña M.R. 2015. Aves argentinas. Buenos Aires: EudebaEdiciones UNL.

Di Giacomo A.S. \& Di Giacomo A.G. 2004. Extinción, historia natural y conservación de las poblaciones del Yetapá de Collar (Alectrurus risora) en la Argentina. Ornitología Neotropical 15: $145-157$.

Di Giacomo A.S. \& Lopez-de-Casenave J. 2010. Use and importance of crop and field-margin habitats for birds in a Neotropical agricultural ecosystem. Condor 112: 283-293.

Dotta G., Phalan B., Silva T.W., Green R. \& Balmford A. 2016. Assessing strategies to reconcile agriculture and bird conservation in the temperate grasslands of South America. Conservation Biology 30: 618-627.

Duchardt C.J., Miller J.R., Debinski D.M. \& Engle D.M. 2016. Adapting the fire-grazing interaction to small pastures in a fragmented landscape for grassland bird conservation. Rangeland Ecology \& Management 69: 300-309.

Ellison K.S., Ribic C.A., Sample D.W., Fawcett M.J. \& Dadisman J.D. 2013. Impacts of tree rows on grassland birds and potential nest predators: a removal experiment. PLoS ONE 8: e59151.

Evans K.L. 2004. The potential for interactions between predation and habitat change to cause population declines of farmland birds. Ibis 146: 1-13.

Filloy J. \& Bellocq M.I. 2007. Patterns of bird abundance along the agricultural gradient of the Pampean region. Agriculture, Ecosystems \& Environment 120: 291-298.

Flaspohler D.J., Temple S.A. \& Rosenfield R.N. 2001. Species-specific edge effects on nest success and breeding bird density in a forested landscape. Ecological Applications 11: 32-46.

Fletcher R.J. \& Koford R.R. 2003. Spatial responses of Bobolinks (Dolichonyx oryzivorus) near different types of edges in northern Iowa. Auk 120: 799-810.

Fletcher K., Aebischer N.J., Baines D., Foster R. \& Hoodless A.N. 2010. Changes in breeding success and abundance of groundnesting moorland birds in relation to the experimental deployment of legal predator control. Journal of Applied Ecology 47: 263-272.

Forman R.T.T. \& Alexander L.E. 1998. Roads and their major ecological effects. Annual Review of Ecology and Systematics 29: 207-231. 
Fraga R.M. 2003. Distribution, natural history and conservation of the Black-and-white Monjita (Heteroxolmis dominicana) in Argentina, a species vulnerable to extinction. Ornitología Neotropical 14: $145-156$.

Grueber C.E., Nakagawa S., Laws R.J. \& Jamieson I.G. 2011. Multimodel inference in ecology and evolution: challenges and solutions. Journal of Evolutionary Biology 24: 699-711.

Hinsley S.A. \& Bellamy P.E. 2000. The influence of hedge structure, management and landscape context on the value of hedgerows to birds: a review. Journal of Environmental Management 60: 33-49.

Hogrefe T.C., Yahner R.H. \& Piergallini N.H. 1998. Depredation of artificial ground nests in a suburban versus a rural landscape. Journal of the Pennsylvania Academy of Science 72: 3-6.

Huijser M.P. \& Clevenger A.P. 2006. Habitat and corridor function of rights-of-way, p. 233-254. In: Davenport J. \& Davenport J. (eds.). The ecology of transportation: managing mobility for the environment. Dordrecht: Springer.

Isacch J.P. \& Martínez M.M. 2001. Estacionalidad y relaciones con la estructura del hábitat de la comunidad de aves de pastizales de Paja Colorada (Paspalum quadrifarium) manejados con fuego en la provincia de Buenos Aires, Argentina. Ornitología Neotropical 12: 345-354.

King D.I., Chandler R.B., Collins J.M., Wayne R.P. \& Thomas E.L. 2009. Effects of width, edge and habitat on the abundance and nesting success of scrub-shrub birds in powerline corridors. Biological Conservation 142: 2672-2680.

Kociolek A.V., Clevenger A.P., St. Clair C.C. \& Proppe D.S. 2011. Effects of road networks on bird populations. Conservation Biology 25: 241-249.

Leston L. 2013. Transmission lines as tall-grass prairie habitats: local mowing, spraying, and surrounding urbanization as determinants of wildlife richness and abundance. Ph.D. Thesis. Manitoba: University of Manitoba.

Leveau L.M. \& Leveau C.M. 2011. Uso de bordes de cultivo por aves durante invierno y primavera en la Pampa austral. Hornero 26: 159-161.

McDonald D.W. \& Johnson P.J. 1995. The relationship between bird distribution and the botanical and structural characteristics of hedges. Journal of Applied Ecology 32: 492-505.

Massoni V. \& Reboreda J.C. 2002. A neglected cost of brood parasitism: egg punctures by Shiny Cowbirds during inspection of potential host nests. Condor 104: 407-412.

Matteucci S.D. \& Colma A. 1982. Metodología para el estudio de la vegetación. Washington: OEA.

Meunier F.D., Verheyden C. \& Jouventin P. 1999. Bird communities of highway verges: influence of adjacent habitat and roadside management. Acta Oecologica 20: 1-13.

Patten M.A., Shochat E., Reinking D.L., Wolfe D.H. \& Sherrod S.K. 2006. Habitat edge, land management, and rates of brood parasitism in tallgrass prairie. Ecological Applications 16: 687-695.

Pietz P.J., Buhl D.A., Shaffer J.A., Winter M. \& Johnson D.H. 2009. Influence of trees in the landscape on parasitism rates of grassland passerine nests in southeastern North Dakota. Condor 111: 3642.

Port J. \& Schottler S. 2017. The effect of floristic composition on bird communities in a set of four grassland reconstruction types. Ecological Restoration 35: 112-119.

Pretelli M.G., Isacch J.P. \& Cardoni D.A. 2018. Species-area relationships of specialist versus opportunistic Pampas grassland birds depend on the surrounding landscape matrix. Ardeola 65: 3-23.

R Core Team. 2019. R: a language and environment for statistical computing, v. 3.3.1. Vienna: R Foundation for Statistical Computing.
Reif J. 2013. Long-term trends in bird populations: a review of patterns and potential drivers in North America and Europe. Acta Ornithologica 48: 1-16.

Remsen-Jr. J.V., Areta J.I., Cadena C.D., Claramunt S., Jaramillo A., Pacheco J.F., Pérez Emán J., Robbins M.B., Stiles F.G., Stotz D.F. \& Zimmer K.J. 2019. A classification of the bird species of South America. Louisiana: American Ornithological Society.

Robinson R.A., Hart J.D., Holland J.M. \& Parrott D. 2004. Habitat use by seed-eating birds: a scale-dependent approach. Ibis 146 : 87-98.

Santabárbara J., Rubio E. \& Martínez T. 2016. Manual de análisis de supervivencia: curvas de supervivencia y regresión de Cox. Zaragoza: Prensas de la Universidad de Zaragoza.

Seiler A. 2001. Ecological effects of roads: a review. Uppsala: Swedish University of Agricultural Sciences.

Smucker K.M., Hutto R.L. \& Steele B.M. 2005. Changes in bird abundance after wildfire: importance of fire severity and time since fire. Ecological Applications 15: 1535-1549.

Söderström B., Pärt T. \& Rydén J. 1998. Different nest predator faunas and nest predation risk on ground and shrub nests at forest ecotones: an experiment and a review. Oecologia 117: 108-118.

Soriano O., León R.J.C., Sala O.E., Lavado R.S., Deregibus V.A., Cauhepé M.A., Scaglia O.A., Velázquez C.A. \& Lemcoff J.H. 2001. Río de La Plata grassland, p. 367-407. In: Coupland R.T. (ed.). Natural grasslands: introduction and Western Hemisphere. Amsterdam: Elsevier.

Sullivan D. 2009. Google Earth Pro. EContent 32: 16-18.

Svagelj W.S., Mermoz M.E. \& Fernández G.J. 2003. Effect of egg type on the estimation of nest predation in passerines. Journal of Field Ornithology 74: 243-249.

Therneau T.M. \& Therneau M.T.M. 2018. Package "coxme": mixed effects cox models. R package v. 2.2-10.

Thompson F.R. \& Burhans D.E. 2004. Differences in predators of artificial and real songbird nests: evidence of bias in artificial nest studies. Conservation Biology 18: 373-380.

Vervoorst F.B. 1967. La vegetación de la República Argentina: VII (las comunidades vegetales de la Depresión del Salado - provincia de Buenos Aires). Buenos Aires: INTA.

Vickery J.A., Feber R.E. \& Fuller R.J. 2009. Arable field margins managed for biodiversity conservation: a review of food resource provision for farmland birds. Agriculture, Ecosystems \& Environment 133: 1-13.

Viglizzo E.F., Frank F.C. \& Carreño L.V. 2011. Ecological and environmental footprint of 50 years of agricultural expansion in Argentina. Global Change Biology 17: 959-973.

Weidinger K. 2002. Interactive effects of concealment, parental behaviour and predators on the survival of open passerine nests. Journal of Animal Ecology 71: 424-437.

Weidman T. \& Litvaitis J.A. 2011. Are small habitat patches useful for grassland bird conservation? Northeastern Naturalist 18: 207-216.

Weldon A.J. \& Haddad N.M. 2005. The effects of patch shape on Indigo Buntings: evidence for an ecological trap. Ecology 86: 1422-1431.

Wilson G.R., Brittingam M.C. \& Goodrich L.J. 1998. How well do artificial nests estimate success of real nests? Condor 100: 357-364.

Zanette L. \& Jenkins B. 2000. Nesting success and nest predators in forest fragments: a study using real and artificial nests. Auk 117: 445-454.

Zuckerberg B., Porter W.F. \& Corwin K. 2009. The consistency and stability of abundance: occupancy relationships in large-scale population dynamics. Journal of Animal Ecology 78: 172-181.

Associate Editor: Caio G. Machado. 


\section{APPENDIX I}

Birds recorded using roadside borders of the Argentine Pampas ( $n=90$ sampling plots). In every plot, the maximum abundance of each species recorded across samplings (October and November) was used. Total individuals of each species summed those detected over the 90 sampling plots. $\left(^{*}\right)$ Grassland ground nesting species. $\left.{ }^{* *}\right)$ Grassland obligates.

\begin{tabular}{llll}
\hline Order, Family, Species & Total individuals & Presence (\%) & Mean abundance \\
\hline TINAMIFORMES & &
\end{tabular}

\section{Tinamidae}

Rhynchotus rufescens $* * *$

Nothura maculosa ***

\section{ANSERIFORMES}

\section{Anhimidae}

Chauna torquata

\section{Anatidae}

Dendrocygna viduata

Callonetta leucophrys

Spatula versicolor

Anas georgica

Anas flavirostris

Netta peposaca

\section{PODICIPEDIFORMES}

\section{Podicipedidae}

Rollandia rolland

Podilymbus podiceps

Podiceps major

\section{COLUMBIFORMES}

\section{Columbidae}

Patagioenas picazuro

Zenaida auriculata

Columbina picui

\section{CUCULIFORMES}

\section{Cuculidae}

Guira guira

\section{GRUIFORMES}

\section{Aramidae}

Aramus guarauna

\section{Rallidae}

Pardirallus maculatus

Pardirallus sanguinolentus

Porphyriops melanops

Fulica rufifrons

Fulica armillata

\section{APODIFORMES}

\section{Trochilidae}


\begin{tabular}{l} 
Order, Family, Species \\
\hline CHARADRIIFORMES
\end{tabular}

Total individuals

Presence (\%)

Mean abundance

\section{Charadriidae}

Vanellus chilensis ***

Recurvirostridae

Himantopus mexicanus

Laridae

Chroicocephalus maculipennis

Gelochelidon nilotica

\section{SULIFORMES}

Phalacrocoracidae

Phalacrocorax brasilianus

PELECANIFORMES

\section{Ardeidae}

Ardea alba

Egretta thula

\section{ACCIPITRIFORMES}

\section{Accipitridae}

Elanus leucurus

Rostrhamus sociabilis

Circus buffoni

0.05

Rupornis magnirostris

\section{PICIFORMES}

\section{Picidae}

Colaptes melanochloros

Colaptes campestris

\section{FALCONIFORMES}

Falconidae

Caracara plancus

Milvago chimango

PSITTACIFORMES

Psittacidae

Myiopsitta monachus

PASSERIFORMES

\section{Furnariidae}

Furnarius rufus

Phleocryptes melanops

Leptasthenura platensis

2.22

0.02

Phacellodomus striaticollis

Anumbius annumbi

21.11

0.31

Limnoctites sulphuriferus

24.44

0.38

Synallaxis albescens 


\begin{tabular}{|c|c|c|c|}
\hline Order, Family, Species & Total individuals & Presence (\%) & Mean abundance \\
\hline \multicolumn{4}{|l|}{ Tyrannidae } \\
\hline Serpophaga nigricans & 8 & 7.77 & 0.08 \\
\hline Serpophaga subcristata & 1 & 1.11 & 0.01 \\
\hline Pseudocolopteryx flaviventris & 61 & 38.88 & 0.67 \\
\hline Tachuris rubrigastra & 8 & 5.55 & 0.08 \\
\hline Pyrocephalus rubinus & 14 & 10 & 0.15 \\
\hline Hymenops perspicillatus & 144 & 74.44 & 1.6 \\
\hline Satrapa icterophrys & 7 & 6.66 & 0.07 \\
\hline Machetornis rixosa & 2 & 2.22 & 0.02 \\
\hline Pitangus sulphuratus & 57 & 35.55 & 0.63 \\
\hline Tyrannus melancholicus & 17 & 13.33 & 0.18 \\
\hline Tyrannus savana & 64 & 37.77 & 0.71 \\
\hline \multicolumn{4}{|l|}{ Hirundinidae } \\
\hline Progne tapera & 9 & 6.66 & 0.1 \\
\hline Progne chalybea & 3 & 3.33 & 0.03 \\
\hline Tachycineta leucorrhoa & 24 & 20 & 0.26 \\
\hline Hirundo rustica & 128 & 28.88 & 1.42 \\
\hline \multicolumn{4}{|l|}{ Troglodytidae } \\
\hline Troglodytes aedon & 25 & 22.22 & 0.27 \\
\hline Cistothorus platensis & 1 & 1.11 & 0.01 \\
\hline \multicolumn{4}{|l|}{ Polioptilidae } \\
\hline Polioptila dumicola & 5 & 4.44 & 0.05 \\
\hline \multicolumn{4}{|l|}{ Turdidae } \\
\hline Turdus rufiventris & 5 & 5.55 & 0.05 \\
\hline \multicolumn{4}{|l|}{ Mimidae } \\
\hline Mimus saturninus & 14 & 10 & 0.15 \\
\hline \multicolumn{4}{|l|}{ Motacillidae } \\
\hline Anthus correndera ${ }^{* * *}$ & 3 & 3.33 & 0.03 \\
\hline \multicolumn{4}{|l|}{ Fringillidae } \\
\hline Spinus magellanicus & 9 & 6.66 & 0.1 \\
\hline \multicolumn{4}{|l|}{ Passerellidae } \\
\hline Zonotrichia capensis* & 378 & 96.66 & 4.2 \\
\hline \multicolumn{4}{|l|}{ Icteridae } \\
\hline Leistes superciliaris* ** & 1 & 1.11 & 0.01 \\
\hline Molothrus bonariensis & 219 & 73.33 & 2.43 \\
\hline Amblyramphus holosericeus & 19 & 12.22 & 0.21 \\
\hline Agelaioides badius & 58 & 16.66 & 0.64 \\
\hline Agelasticus thilius & 152 & 56.66 & 1.68 \\
\hline Pseudoleistes virescens & 222 & 72.22 & 2.46 \\
\hline \multicolumn{4}{|l|}{ Thraupidae } \\
\hline Sicalis flaveola & 28 & 15.55 & 0.31 \\
\hline Sicalis luteola $* * *$ & 526 & 85.55 & 5.84 \\
\hline Sporophila caerulescens & 8 & 5.55 & 0.08 \\
\hline
\end{tabular}




\begin{tabular}{lccc}
\hline Order, Family, Species & Total individuals & Presence (\%) & Mean abundance \\
\hline Embernagra platensis ${ }^{* *}$ & 111 & 65.55 & 1.23 \\
Poospiza nigrorufa & 64 & 45.55 & 0.71 \\
Donacospiza albifrons ${ }^{*}$ & 6 & 5.55 & 0.06 \\
Paroaria coronata & 1 & 1.11 & 0.01 \\
Pipraeidea bonariensis & 5 & 3.33 & 0.05 \\
\hline
\end{tabular}

